\title{
Frontex en de grenzen van zijn mandaat
}

M.H.A. Strik*

De bewaking van de buitengrenzen van de Europese Unie (EU) is een nationale competentie. Maar vanwege het gemeenschappelijke belang van effectieve controle aan die grenzen hebben de EU-lidstaten in 2004 Frontex opgericht. ${ }^{1}$ Frontex is vaak het mikpunt van kritiek als het misgaat aan de grenzen, bijvoorbeeld wanneer migranten verdrinken of vluchtelingen de toegang tot de EU wordt geweigerd. Maar wat zijn nu precies de taken en verantwoordelijkheden van dit EU-agentschap en hoe verhouden die zich tot de verantwoordelijkheden van de lidstaten zelf? Dit artikel gaat op deze vragen in, maar ook op de mensenrechtelijke dilemma's die optreden bij gezamenlijke operaties. Met de toenemende migratie over zee zijn goede afspraken over de naleving van mensenrechten van levensbelang geworden. Is die naleving gegarandeerd met de grote aantallen vluchtelingen die via een oversteek van de Middellandse Zee proberen om in de EU bescherming te verkrijgen?

\section{Taken}

Door Frontex een coördinerende taak te geven bij acties van de lidstaten aan de buitengrenzen beoogt de EU de bewaking van de buitengrenzen effectiever en meer uniform te maken. Onder de buitengrenzen van de lidstaten worden de land- en zeegrenzen van de lidstaten verstaan, maar ook hun lucht- en zeehavens. Lidstaten beschouwden als belangrijke meerwaarde van Frontex de steun die het agentschap

* Mr. dr. Tineke Strik is als universitair docent verbonden aan het Centrum voor Migratierecht van de Radboud Universiteit Nijmegen. Daarnaast is zij voorzitter van de GroenLinks-fractie in de Eerste Kamer.

1 Het Europees agentschap voor het beheer van de operationele samenwerking aan de buitengrenzen van de lidstaten van de Europese Unie, Verordening 2007/2004 van 26 oktober 2004, PbEG 25 november 2004, L/349. De naam komt van het Franse 'frontières extérieures' (buitengrenzen). 
kan bieden aan lidstaten die te maken krijgen met grootschalige illegale migratie.

Concreet houden de taken van Frontex het volgende in: het coördineren van de operationele samenwerking tussen de lidstaten op het gebied van het beheer van de buitengrenzen, het helpen van de lidstaten bij het opleiden van nationale grenswachten, het uitvoeren van risicoanalyses, het bieden van extra technische en operationele bijstand aan de lidstaten en het uitvoeren en ondersteunen van gezamenlijke terugkeeroperaties. ${ }^{2}$ Frontex kan zelf net als de lidstaten het initiatief nemen voor gezamenlijke operaties en proefprojecten en ook rechtstreeks samenwerken met individuele lidstaten. De zetel van het agentschap is toegekend aan Polen, waar het hoofdkantoor is gevestigd in Warschau. De meeste medewerkers zijn gedetacheerd vanuit de lidstaten: per operatie bepalen lidstaten hoeveel en welk type personeel ze beschikbaar stellen. Ook het materieel (schepen en vliegtuigen) wordt uitgeleend door de lidstaten. De operaties verschillen in omvang en duur.

In zijn relatief korte bestaan heeft Frontex een stormachtige ontwikkeling doorgemaakt. Sinds zijn oprichting zijn de taken en capaciteiten verschillende malen uitgebreid en is de oorspronkelijke oprichtingsverordening tweemaal aangepast. In 2007 is de mogelijkheid toegevoegd om snelle grensinterventieteams (Rapid Border Intervention Teams, afgekort als RABITs) in te zetten die voor een beperkte periode operationele bijstand verlenen aan een verzoekende lidstaat, als die plots te maken krijgt met een hoog aantal migranten dat illegaal de buitengrenzen tracht te overschrijden. ${ }^{3}$ De teams bestaan uit ambtenaren van verschillende lidstaten die tijdelijk worden uitgeleend aan Frontex voor een operatie op het grondgebied van een andere lidstaat. De verordening omschrijft de taken en bevoegdheden van de teamleden. Bij de uitvoering van hun taken dragen teamleden hun eigen uniform. Daarop dragen ze een blauwe armband met het insigne van de EU en van Frontex, zodat ze als lid van een ingezet team kunnen worden geïdentificeerd.

2 Art. 2 lid 1 Verordening 2007/2004.

3 Verordening 863/2007 van 11 juli 2007, PbEG 31 juli 2007, L/199. Met migranten wordt hier gedoeld op derdelanders: mensen die niet de nationaliteit hebben van een EU-lidstaat. 


\section{Verhouding tussen Frontex en lidstaten}

Nadat aanvankelijk de lidstaten een supranationaal Europees instituut van grenswachten voor ogen hadden, besloten ze in 2002 tot een agentschap dat de samenwerking, coördinatie en consistentie tussen de nationale grenswachten moest vergemakkelijken, echter zonder deze taken van de lidstaten over te nemen. ${ }^{4}$ Het uitgangspunt is daarom nu dat Frontex een adviserende en assisterende taak heeft bij de grensbewaking van de ontvangende (bijna altijd ook de verzoekende) lidstaat, die zelf eindverantwoordelijk blijft voor de daadwerkelijke handelingen en beslissingen die worden genomen. ${ }^{5}$ Ook bij de gezamenlijke grensinterventieteams ligt de eindverantwoordelijkheid bij de ontvangende lidstaat, zelfs als Frontex de operaties feitelijk initieert en coördineert. Het besluit om een interventieteam in te zetten en de inhoud van het operationele plan vergen de goedkeuring van zowel Frontex als de ontvangende staat. Is de operatie eenmaal van start, dan liggen het commando en de controle over de activiteiten van de grenswachten bij de ontvangende staat. De taken, bevoegdheden en aansprakelijkheden van de nationale grenswachten van andere lidstaten zijn uitgebreid vastgelegd. ${ }^{6}$ In de kern is de positie van deze grenswachten gelijkgesteld met die van de ontvangende lidstaat. Ze worden geacht te zijn ingelijfd in de commandostructuur van deze lidstaat en dienen als zodanig te worden behandeld, ook wat betreft civiele en strafrechtelijke aansprakelijkheid. Het betekent ook dat ze het nationale recht van deze lidstaat moeten naleven en dat de beslissing om iemand de toegang te weigeren wordt genomen door de ontvangende lidstaat; de gedetacheerde grenswachten kunnen niet anders dan instructies hiertoe uitvoeren. Ook mogen ze wapens dragen en ten behoeve van hun taak of uit zelfverdediging geweld gebruiken, in aanwezigheid van collega's van de ontvangende lidstaat. Een geweldsinstructie vergt wel de instemming van zowel het herkomstland als het ontvangende land. Gedetacheerde functionarissen, inclusief uitgezon-

4 Zie de Mededeling van de Commissie 'Naar een geïntegreerd beheer van de buitengrenzen van de lidstaten van de EU', COM(2002)233 en Europese Raad 14 juni 2002, Raadsdocument 9834/1/02 Front 55 COMIX 392 REV, par. IV.

5 Zie considerans nr. 4 Verordening 2007/2004: 'De lidstaten zijn verantwoordelijk voor de controle en de bewaking van de buitengrenzen. Het agentschap moet de toepassing van bestaande en toekomstige communautaire maatregelen in verband met het beheer van de buitengrenzen vergemakkelijken door de acties van de lidstaten ter uitvoering van deze maatregelen te ondersteunen.'

6 Zie art. 12 lid 6 Verordening 863/2007, dat art. 10 Verordening 2007/2004 wijzigt. 
den militairen, genieten geen immuniteit als ze de strafwet overtreden. ${ }^{7}$ Als de ontvangende lidstaat geen gebruik maakt van de mogelijkheid om hen te vervolgen, kan de zendende lidstaat bij thuiskomst van de functionaris daartoe zelf nog overgaan (Voetelink 2011). De regel dat de ontvangende lidstaat aansprakelijk is, geldt alleen tussen de lidstaten, maar niet voor een derde partij die een claim legt ten aanzien van een handeling van een gedetacheerde grenswacht. De zendende lidstaat gaat dus niet helemaal vrijuit als zijn ambtenaar in het ontvangende land een strafbaar feit begaat (Heijer 2012, par. 5.2.2.4).

\section{Mensenrechten aan de grens}

De verdeling van verantwoordelijkheden, maar ook het werken met mensen in een kwetsbare positie en de mogelijke impact van de weigering van toegang tot Europees grondgebied vergen een nauwkeurige vastlegging en monitoring van naleving van de mensenrechten. In de verordening van 2007 is expliciet opgenomen dat het vluchtelingrechtelijk beginsel van niet-uitzetting naar een plaats waar iemand bedreigd wordt met vervolging (non-refoulement) onverminderd van toepassing is. ${ }^{8}$ De verordening verwijst naar de Schengen Grenscode (SGC) van 2006, die het verbod op refoulement voorrang geeft op de plicht om de toegang te weigeren. ${ }^{9}$ Sinds 2009 is Frontex juridisch gebonden aan het EU-Handvest van de Grondrechten, waarin ook enkele waarborgen voor vluchtelingen zijn opgenomen. ${ }^{10}$

De naleving van de mensenrechten door Frontex is verschillende malen ter discussie gesteld. In 2010 vormde Frontex met de operatie Poseidon een snel grensinterventieteam aan de Grieks-Turkse grens. Op een grensstrook van 12,5 kilometer patrouilleerden 175 grenswachten met behulp van warmtebeeldkijkers en speurhonden. Ze onderschepten migranten tijdens hun illegale oversteek en droegen

7 Art. 12 lid 6 Verordening 863/2007, art. 10quater.

8 Zie considerans nr. 22 Verordening 2007/2004 en art. 2 Verordening 863/2007. In considerans $\mathrm{nr} .17$ van deze verordening wordt tevens verwezen naar het Handvest van de Grondrechten.

9 Zie art. 10 Verordening 863/2007, en in de Schengen Grenscode (Verordening 562/2006) considerans nr. 20, art. 3 sub b en 13 lid 1.

10 Zie art. 18, het recht op asiel met inachtneming van het Vluchtelingenverdrag, en art. 19, het verbod van collectieve uitzetting en het verbod om iemand te verwijderen of uitzetten naar een staat waarin een ernstig risico bestaat dat hij aan de doodstraf, aan folteringen of aan andere onmenselijke of vernederende behandelingen of bestraffingen wordt onderworpen. 
hen vervolgens bij de Griekse detentiecentra over aan de Griekse autoriteiten. ${ }^{11}$

In september 2011, vlak voor de totstandkoming van de gewijzigde verordening, was het de ngo Human Rights Watch die Frontex verweet door die overdracht medeschuldig te zijn aan het blootstellen van migranten aan de onmenselijke en vernederende detentieomstandigheden in Griekenland (Human Rights Watch 2011). Het Europees Hof voor de Rechten van de Mens (EHRM) had begin van dat jaar geoordeeld dat de omstandigheden voor migranten in de Griekse detentiecentra in strijd waren met de mensenrechten. ${ }^{12}$

Frontex verklaarde in een reactie erg bezorgd te zijn over de situatie in Griekenland, maar benadrukte dat Griekenland zelf en niet Frontex hiervoor verantwoordelijk is. Frontex liet weten het EU-Handvest te respecteren, daarbij verwijzend naar de Fundamental Rights Strategy. ${ }^{13}$ De verordening die vlak na de publicatie van Human Rights Watch werd aangenomen, legt de naleving van de mensenrechten door Frontex explicieter vast. Het agentschap wordt daarin opgedragen een Grondrechtenstrategie op te stellen en toe te passen bij al zijn activiteiten. ${ }^{14}$ Ook biedt de verordening Frontex meer mogelijkheden om te reageren op schendingen van mensenrechten, met als uiterste middel het opschorten of beëindigen van operationele acties in het geval van een ernstige schending van grondrechten. ${ }^{15}$ Frontex dient bij trainingen aan grenswachten aandacht te besteden aan de grondrechten, toegang tot internationale bescherming en het recht van de zee. ${ }^{16}$ Verder regelde de verordening de instelling van twee toezichthouders: een onafhankelijke grondrechtenfunctionaris en een raadgevend forum waarin verschillende organisaties zijn afgevaardigd. ${ }^{17}$ Dit raadgevend forum hielp Frontex bij het opstellen van een gedragscode om de grondrechten te waarborgen, met name ten aanzien van kwetsbare

11 Zie ook 'Frontex-missie Poseidon. Patrouilleren aan de achterdeur van Europa', KMarMagazine 2010, afl. 12, p. 7-10.

12 EHRM 21 januari 2011, appl. nr. 30696/09, JV 2011/68 (MSS v. België en Griekenland).

13 Frontex Fundamental Rights Strategy. Vastgesteld door de Frontex Management Board op 31 maart 2011.

14 Art. 26 bis lid 1.

15 Art. 3 lid 1 bis.

16 Art. 5 sub a.

17 Art. 26bis lid 2 en 3. In het adviesforum hebben o.a. EASO, Fundamental Rights Agency (FRA), UNHCR en een aantal maatschappelijke organisaties zitting. 
personen en asielzoekers. ${ }^{18}$ Voor gezamenlijke terugkeeroperaties zou een afzonderlijke gedragscode worden opgesteld. ${ }^{19}$

Deze verbeteringen konden echter niet voorkomen dat nieuwe beschuldigingen aan het adres van Frontex werden geuit. In oktober 2013 rapporteerde de Duitse organisatie Pro Asyl uitgebreid over de operaties Poseidon Land and Sea, waarin volgens haar de mensenrechten systematisch werden geschonden. Griekse grenswachten zouden migranten vanaf hun territorium terugslepen naar Turks gebied, zonder enig onderzoek naar hun behoefte aan bescherming. De nongouvernementele organisatie (ngo) Pro Asyl riep de uitvoerend directeur van Frontex daarom op om de operaties in Griekenland te beëindigen (Pro Asyl 2013). Amnesty International deed dezelfde aanbeveling en vermeldde in zijn rapport dat Frontex om opheldering had verzocht bij de Griekse autoriteiten, die enkele beschuldigingen ontkenden en andere in onderzoek hadden genomen. Een joint follow-up team zou deze onderzoeken monitoren. Amnesty bekritiseerde dat Frontex geen openheid gaf over zijn bevindingen naar organisaties die de mensenrechtenschendingen hadden gesignaleerd (Amnesty International 2014, p. 26-28).

Deze commentaren roepen ook steeds de vraag op wie politiek en juridisch verantwoordelijk is in geval van mensenrechtenschendingen tijdens (gezamenlijke) grensbewakingsoperaties: de lidstaat waarbij de grenswacht (tijdelijk) in dienst is, de lidstaat die de grenswacht heeft gedetacheerd of Frontex, als deze grenswacht het embleem van het agentschap draagt (Den Heijer 2012, par. 6.2)? In reactie op de kritiek van Amnesty liet Frontex weten dat de Griekse grenswachten die deelnamen aan de Poseidon-operaties geen embleem van Frontex droegen (Amnesty International 2014, p. 27). Dit maakt het voor mogelijke slachtoffers van mensenrechtenschendingen nog onduidelijker tot wie ze zich moeten wenden.

Met de advisering en zeker met de coördinatie heeft Frontex invloed op de handelingen van de uitvoerende ambtenaren, vaak meer dan de ontvangende staat zelf. Het is daarom zeer de vraag of Frontex altijd buiten schot kan blijven als het betrokken is bij acties die leiden tot mensenrechtenschendingen. De Europese Ombudsman vindt in elk geval van niet. Hij stelde een zelfstandig onderzoek in naar de wijze waarop Frontex het Handvest van de Grondrechten implementeert. In 
reactie op zijn vraag of er een klachtenprocedure is voor personen die geschaad worden door de activiteiten van Frontex, antwoordde het agentschap dat het slechts een coördinerende functie heeft en dat alleen de nationale autoriteiten activiteiten kunnen ontplooien die klachten oproepen. De Ombudsman nam daar geen genoegen mee en riep Frontex op om een klachtenprocedure in te stellen voor individuen die menen dat hun grondrechten zijn geschonden door Frontexoperaties (Europese Ombudsman 2013). Het agentschap heeft hieraan geen gehoor gegeven. Naast tal van andere aanbevelingen riep de Ombudsman Frontex ook op om in de grondrechtenstrategie te verduidelijken wanneer het zich verantwoordelijk beschouwt voor schending van grondrechten tijdens operaties. Ook hierop bleef het stil. In oktober 2014 opende de Ombudsman een nieuw onderzoek, dit keer naar de toepassing van de waarborgen en de gedragscode bij Frontexterugkeeroperaties (Europese Ombudsman 2014).

\section{Mensenrechten op zee}

De kwetsbaarheid van migranten aan de grens is het meest pregnant als de grensbewaking zich afspeelt op zee. Juist daar opereren de grootste en kostbaarste gezamenlijke patrouilles. Geregeld zijn daar ook derde landen bij betrokken; zo werden tijdens de Hera-operaties bij de Canarische Eilanden grenswachten van Mauritanië en Senegal actief ingezet om onderschepte migranten te laten terugkeren (Carrera 2007). Door samenwerkingsovereenkomsten met derde landen mogen Frontex-operaties zich ook uitstrekken over de territoriale wateren van deze landen. ${ }^{20}$

Met gezamenlijke patrouilles in de internationale wateren en in die van derde landen komen de controles steeds verder van de fysieke EUgrenzen te liggen, waardoor migranten moeilijker het EU-territorium kunnen bereiken. Dit is vooral problematisch als zij de intentie hebben om een asielverzoek in te dienen in de EU. Als hun dat onmogelijk

20 De basis van de bilaterale samenwerking met derde landen ligt meestal in een Memorandum of Understanding, dat geen parlementaire instemming behoeft. De bevoegdheid van Frontex om in derde landen te opereren baseert het waarschijnlijk op art. 12 SGC (dit noemt als doel van grenscontrole het voorkomen van ongeautoriseerde grensoverschrijding) en art. 14 Verordening 2007/2004 (dit noemt het doel van Frontex om de samenwerking tussen de lidstaten en derde landen te vergemakkelijken). Zie Rijpma 2010. 
wordt gemaakt, lopen deze vluchtelingen het risico te worden teruggestuurd naar een oorlogsland of een onveilig transitland.

Dat onderschepping van migranten in deze wateren in overeenstemming gebeurt met de fundamentele rechten, is daarom van eminent belang. Het EHRM heeft hiervoor in 2012 met de zaak Hirsi Jamaa tegen Italië een belangrijke maatstaf aangelegd. In deze zaak klaagde een groep Somaliërs en Eritreeërs dat de Italiaanse kustwacht hen had onderschept in de internationale wateren en rechtstreeks had teruggebracht naar Libië, waar ze werden overgedragen aan de Libische autoriteiten. ${ }^{21}$ Het Hof bepaalde dat de Italiaanse kustwacht 'effectieve controle' had over deze mensen en daarmee rechtsmacht over hen uitoefende. Om die reden diende het handelen van de Italiaanse ambtenaren in overeenstemming te zijn met het Europees Verdrag tot bescherming van de rechten van de mens en de fundamentele vrijheden (EVRM). ${ }^{22}$ Italië had volgens het Hof zich eerst op basis van een individueel onderzoek ervan moeten verzekeren dat de migranten geen risico zouden lopen op een onmenselijke behandeling bij terugkeer in Libië. Het Hof nam daarbij in ogenschouw dat Italië kennis had van de systematische mensenrechtenschendingen in Libië. ${ }^{23}$ Zoals hierboven al beschreven, zijn andere lidstaten (Griekenland, Bulgarije, Spanje) ook na dit arrest nog geregeld beschuldigd van push back-acties. Deels betreffen deze beschuldigingen ook Frontex-operaties (Italian Council for Refugees 2014).

Bij de operaties op zee grijpen twee rechtsgebieden in elkaar: het recht van de zee (inclusief de plicht om mensen in nood op zee te zoeken en redden) en het vluchtelingenrecht. Op beide terreinen kunnen verschillen in toepassing en interpretaties tot geschillen of onduidelijkheden leiden. Bijvoorbeeld over de vraag welke lidstaat verantwoordelijk is voor de ontscheping van geredde migranten, wanneer er sprake is van een noodsituatie (zodat tot een reddingsactie moet worden overgegaan) of wanneer een derde land niet veilig genoeg is om een migrant direct naar terug te sturen. Om eenduidigheid te verkrijgen tijdens gezamenlijke operaties op zee hebben Raad en Parlement in

21 Het rechtstreeks terugsturen of overdragen van migranten zonder onderzoek naar hun veiligheid wordt een 'push back'-actie genoemd.

22 Hier waren met name art. 3 en 13 EVRM en art. 4 Vierde Protocol bij het EVRM (verbod op collectieve uitzetting) in het geding.

23 EHRM (Grote kamer) 23 februari 2012, appl. nr. 27765/09, JV 2012/171 m.nt. M.Y.A. Zieck (Hirsi Jamaa e.a. v. Italië). 
2014 een verordening aangenomen die exact ziet op deze situaties. ${ }^{24}$ De verordening geeft definities van een noodsituatie waarbij het team moet overgaan tot een reddingsactie. ${ }^{25}$ De verordening bevat verder bindende regels ten aanzien van onderschepte of geredde personen: wanneer zij naar welk land dienen te worden gebracht (inclusief de plicht voor ontscheping van de betreffende lidstaat), hoe hun veiligheid daarbij kan worden geborgd en hoe dient te worden omgegaan met een asielverzoek. Met deze regels geeft de Unie ook gedeeltelijk vorm aan de consequenties van het eerdergenoemde Hirsi-arrest. Wetenschappers en organisaties wijzen erop dat in enkele waarborgen die het EHRM benadrukte niet is voorzien, zoals het recht op beroep in de zin van artikel 13 EVRM als ter plekke op een asielverzoek wordt beslist. Dit geldt eveneens voor essentiële garanties tijdens een asielprocedure, zoals vertalers en juridische bijstand, waarvan de beschikbaarheid volgens de verordening in het operationeel plan moet worden geregeld. ${ }^{26}$ Het is moeilijk voor te stellen dat migranten aan boord van een marineschip een zorgvuldige asielprocedure kunnen doorlopen, dus eigenlijk zouden migranten toch naar Europees grondgebied moeten worden gebracht als zij te kennen geven een asielverzoek te willen indienen.

De verordening biedt perspectief om bij incidenten vragen rondom aansprakelijkheid op te lossen. De standaarden van de VN-verdragen inzake het recht van de zee zijn nu feitelijk gecodificeerd in EU-wetgeving en de lidstaten kunnen deze niet meer verschillend interpreteren. ${ }^{27}$ Ook Frontex zelf is nu gebonden aan het recht van de zee. Toch kent de verordening ernstige beperkingen, omdat ze alleen van toepassing is tijdens gezamenlijke Frontex-operaties en niet in de territoriale wateren of op het grondgebied van derde landen. Omdat Frontex echter gebonden is aan het EU-Handvest, dient het agentschap ook in het territorium van derde landen zich te onthouden van push backs van migranten. Als dat derde land niet veilig is voor migranten of

24 Verordening tot vaststelling van regels voor de bewaking van de zeebuitengrenzen in het kader van de operationele samenwerking gecoördineerd door Frontex, Verordening 656/2014 van 13 mei 2014, PbEU 27 juni 2014, L/189. Deze verordening vervangt Besluit 2010/252/EU van 26 april 2010, dat in 2012 is vernietigd door het Hof van Justitie, HvJ EU 5 september 2012, C-355/10 (Parlement v. Raad).

25 Zie art. 9 van de verordening.

26 Art. 4 van de verordening. Zie voor commentaar: Meijers Committee 2013, p. 2-3; Amnesty International e.a. 2013.

27 Het VN-zeerechtverdrag van 1982 en het Internationaal Verdrag voor de veiligheid van mensenlevens op zee van 1974 (in werking getreden in 1980). 
vluchtelingen, mag Frontex evenmin meewerken aan het belemmeren van hun vertrek uit dat land op weg naar bescherming in Europa.

\section{Mare Nostrum}

Sinds het uitbreken van de oorlog in Libië in 2011 nam het geweld tegen migranten verder toe, en daarmee ook het aantal migranten dat de oversteek waagde naar Italië. Niet alle migranten die op zee in nood verkeerden, werden daarbij gered (zie ook Strik 2012, 2014). In oktober 2013 leidde de verdrinking van meer dan 300 mensen nabij Lampedusa tot internationale beroering. Italië besloot tot een grootscheepse militaire reddingsactie in de internationale wateren, genaamd Mare Nostrum, gericht op het onderscheppen en redden van migranten en het arresteren van mensensmokkelaars. In de periode dat deze reddingsoperatie actief was, van 18 oktober 2013 tot 1 november 2014, onderschepte Mare Nostrum 150.810 personen en bracht hen naar Italiaans grondgebied. ${ }^{28}$ De Italiaanse actie leidde er ook toe dat de gezamenlijke Frontex-acties Hermes en Aeneas, die sinds 2011 op verzoek van Italië deels in hetzelfde gebied opereerden, aanzienlijk minder personen onderschepten en smokkelaars arresteerden. ${ }^{29}$

Sinds medio 2014 ijverde Italië bij de EU voor financiële en operationele overname van de activiteiten van Mare Nostrum door Frontex. Dit verzoek leverde terughoudende reacties op bij de andere lidstaten. Sommige lidstaten vroegen zich openlijk af of Mare Nostrum niet juist meer illegale migratie uitlokte. Volgens de Nederlandse regering zou de EU, door dicht bij de Libische kust te patrouilleren, het verkeerde signaal afgeven dat de illegale en gevaarlijke overtocht veilig(er) is geworden en zo mensensmokkelaars in de kaart spelen. ${ }^{30}$ De Italiaanse regering heeft echter steeds benadrukt dat Mare Nostrum een antwoord was op het toenemend aantal overstekende migranten en verdrinkingen.

28 Mare Nostrum verving de op dat moment operationele Constant Vigilance, zie Carrera \& Den Hertog 2015, p. 3-4.

29 Hermes onderschepte 64.647 mensen in 2013, maar slechts 28.953 mensen in 2014. Het arresteerde 204 smokkelaars in 2013, maar slechts 76 in 2014 (zie Carrera \& Den Hertog 2015, p.7).

30 Zie o.a. antwoorden op Kamervragen over het bericht 'VN roepen op tot reddingsplan', 25 maart 2015, kenmerk $2015 Z 02749$. 
Onder de aanhoudende druk om toch actie te ondernemen, besloot de Raad om de Frontex-capaciteit in die regio uit te breiden. Op 1 november 2014 werd de operatie Triton gelanceerd, ter vervanging van de Hermes- en Aeneas-operaties. Aangezien Triton een derde van de capaciteit van Mare Nostrum had en slechts tot 30 mijl uit de Italiaanse kust zou patrouilleren, werd Triton niet beschouwd als vervanger of opvolger van Mare Nostrum (Carrera \& Den Hertog 2015, p. 7-10). Het belangrijkste verschil zat hem echter in het mandaat: waar Frontex lidstaten ondersteunt bij de grensbewaking, was Mare Nostrum een humanitaire reddingsoperatie, uitgerust met schepen en personeel gericht op hulpverlening aan grote groepen mensen. Kritiek op dit verschillende karakter wuifden Frontex en de lidstaten weg met het argument dat Frontex zich uiteraard ook houdt aan de plicht om mensen in nood te redden. Maar omdat de meeste boten in de problemen komen bij de Libische kust of in de internationale wateren, voorspelden velen dat Triton meestal te laat ter plekke zou zijn om alle levens te redden. ${ }^{31}$

De voorspellingen kwamen uit: eind april 2015 waren in dat jaar al bijna 1.800 migranten omgekomen in de Middellandse Zee. De dood van 700 migranten in die maand als gevolg van een gekapseisde boot bracht de EU-regeringsleiders er alsnog toe om de Triton-operatie op te schalen tot de capaciteit van de voormalige Mare Nostrum-operatie. Het mandaat zou ongewijzigd blijven (de EU hechtte eraan dat grensbewaking vooropstaat), maar volgens de Europese Raad zou het besluit tot opschaling de zoek- en reddingsmogelijkheden toch vergroten. ${ }^{32}$ Verder zou de EU de VN om een mandaat verzoeken om met militaire middelen de mensensmokkel aan te pakken in Libië. Uit de verklaring van de Raad is tevens op te maken dat ook Frontex in Libië zelf wordt ingezet bij deze acties. Hoewel deze plannen gericht zijn op het afweren van de komst van migranten en vluchtelingen naar Europa, valt niet te vermijden dat de EU met haar aanwezigheid in Libië meer en meer verantwoordelijk wordt voor de veiligheid van de vluchtelingen ter plekke.

31 Zie bijv. de persverklaring van Amnesty International, 'JHA Council: Operation Triton cannot replace Operation Mare Nostrum', van 14 oktober 2014, www.amnesty.nl.

32 Bijzondere vergadering van de Europese Raad, 23 April 2015 - Verklaring, www.consilium. europa.eu/en/press/press-releases/2015/04/23-special-euco-statement/. 


\section{Conclusie}

In zijn elfjarige bestaan zijn de omvang en betekenis van Frontex exponentieel gegroeid. Ondanks de uitbreiding van taken en bevoegdheden blijft het adagium dat Frontex slechts assisteert en geen eigen verantwoordelijkheid draagt, ongewijzigd. Het is de vraag of dit uitgangspunt nog houdbaar is. Ook de uitvoering van taken zoals advisering, coördinatie en feitelijke bijstand kan immers gevaarzetting of zelfs mensenrechtenschendingen tot gevolg hebben. Tegelijkertijd mogen responsibility shifting tussen de betrokken actoren en de kritiek op Frontex niet de andere kant uit werken, in die zin dat lidstaten zich verschuilen achter Frontex en zelf vrijuit gaan bij handelingen die de grondrechten raken.

Verhaal kunnen halen als individu omdat je rechten zijn geschonden, is essentieel in een rechtsstaat en versterkt ook het lerend vermogen van de betreffende organisatie. Het kunnen aanspreken van Frontex is daarom van groot belang. Het zou ook betekenen dat er vaker een beroep kan worden gedaan op het Handvest van de Grondrechten. Lidstaten die in de internationale wateren opereren, kunnen onder bepaalde voorwaarden worden aangesproken op hun verplichtingen van het EVRM, maar niet op die van het Unierecht. Dat is anders voor Frontex, dat als EU-agentschap altijd, ongeacht de plaats van handeling, naast de internationale verplichtingen ook het Handvest dient te respecteren.

De verplichtingen van het Handvest gelden immers onverminderd als Frontex in derde landen opereert. Als fundamentele rechten en grensbewaking botsen, zal de prioriteit bij de fundamentele rechten moeten liggen. Om te voorkomen dat Frontex medeverantwoordelijk wordt voor schending van de fundamentele rechten, zou het alleen moeten samenwerken met derde landen die deze rechten zelf waarborgen. Deze garantie ontbreekt momenteel; in Libië bijvoorbeeld is dit evident het geval. Het opereren in deze landen kan als ultieme consequentie hebben dat Frontex vluchtelingen een veilige route naar de EU zal moeten bieden als het geen veiligheid ter plekke kan garanderen. Met het verleggen van de grensbewaking schuiven de grenzen aan het mandaat van Frontex vanzelf mee. 


\section{Literatuur}

\section{Amnesty International 2014}

Amnesty International, Greece:

Frontier of hope and fear.

Migrants and refugees pushed back at Europe's border, Londen 2014.

Amnesty International e.a. 2013

Amnesty International, International Commission of Jurists and the European Council on Refugees and Exiles, Joint briefing on the European Commission Proposal for a Regulation of the European Parliament and of the Council establishing rules for the surveillance of the external sea borders in the context of operational cooperation coordinated by Frontex, 6 september 2013.

\section{Carrera 2007}

S. Carrera, The EU border management strategy. Frontex and the challenges of irregular immigration in the Canary Islands, CEPS Working Document no. 261, Brussel 2007.

\section{Carrera \& Den Hertog 2015}

S. Carrera \& L. den Hertog, Whose Mare? Rule of law challenges in the field of European border surveillance in the Mediterranean, CEPS Paper no. 79, Brussel 2015.

\section{Europese Ombudsman 2013} Europese Ombudsman, Draft recommendation of the European Ombudsman in his own-initiative inquiry OI/5/2012/BEH-MHZ concerning the European Agency for the Management of Operational Cooperation at the External Borders of the Member States of the European Union (Frontex), 12 november 2013.

\section{Europese Ombudsman 2014}

Europese Ombudsman, Fundamental rights and forced returns of migrants: Ombudsman opens investigation, Press Release no. 20, 22 oktober 2014.

\section{Den Heijer 2012}

M. den Heijer, Europe and extraterritorial asylum, Oxford: Hart Publishing 2012.

\section{Human Rights Watch 2011}

Human Rights Watch, The EU's dirty hands. Frontex involvement in ill-treatment of migrant detainees in Greece, september 2011.

\section{Italian Council for Refugees} 2014

Italian Council for Refugees, Access to protection: Bridges not walls, Rome 2014. 


\section{Meijers Committee 2013}

Meijers Committee, Note on the Proposal for a Regulation establishing rules for the surveillance of the external sea borders in the context of operational cooperation coordinated by Frontex, Utrecht 25 mei 2013.

\section{Pro Asyl 2013}

Pro Asyl, Pushed back, systematic human rights violations against refugees in the Aegean sea and at the Greek-Turkish land border, Frankfurt 2013.

\section{Rijpma 2010}

J.J. Rijpma, Frontex: Successful blame shifting of the member states?, ARI Paper no. 69/2010, Madrid 2010.

\section{Strik 2012}

T. Strik, Lives lost in the Mediterranean Sea: Who's responsible, Parliamentary Assembly Council of Europe, Document no. 12617, Resolution no. 1872, 29 maart 2012.

\section{Strik 2014}

T. Strik, The 'left-to-die' boat: Actions and reactions, Parliamentary Assembly Council of Europe, Document no. 13532, Resolution no. 1999, 9 juni 2014.

\section{Voetelink 2011}

J. Voetelink, 'Frontex, grenzen aan Status of Forces?', Militair Rechtelijk Tijdschrift 2011, p. 144-152. 